\title{
Two-Stage Operations in Patients with Acute Right- sided Colonic Obstruction: A 15-year Single Institution Experience
}

\section{Chun-Wei Yu}

Tri-Service General Hospital

Nien-Ying Tsai

Tri-Service General Hospital

Cheng-Wen Hsiao

Tri-Service General Hospital

Shu-Wen Jao

Tri-Service General Hospital

Yi-Chiao Cheng ( $\nabla$ ndmcjoe@gmail.com )

Tri-Service General Hospital

\section{Research Article}

Keywords: Colon cancer, Obstruction, lleostomy, Two-stage resection

Posted Date: February 23rd, 2021

DOl: https://doi.org/10.21203/rs.3.rs-223101/v1

License: (9) This work is licensed under a Creative Commons Attribution 4.0 International License. Read Full License 


\section{Two-Stage Operations in Patients with Acute}

\section{Right-sided Colonic Obstruction: a 15-year}

\section{Single Institution Experience}

Chun-Wei Yu, MD ${ }^{1}$, Nien-Ying Tsai, MD ${ }^{2}$, Cheng-Wen Hsiao, MD ${ }^{1}$, Shu-Wen Jao, $\mathrm{MD}^{1}$, Yi-Chiao Cheng, $\mathrm{MD}^{1}$

Division of Colon and Rectal Surgery, Department of Surgery, Tri-Service General Hospital, National Defense Medical Center, Taipei, Taiwan ${ }^{1}$; National Defense Medical Center, Taipei, Taiwan ${ }^{2}$

*Corresponding author:

Yi-Chiao Cheng, M.D.

Division of Colon and Rectal Surgery, Department of Surgery, Tri-Service General Hospital, National Defense Medical Center, Taipei, Taiwan

No. 325, Section 2, Cheng-Kong Rd., Neihu District, Taipei 114, Taiwan, ROC.

Tel: +886-2-8792-7209; Fax: +886-2-87927411

E-mail:ndmcjoe@gmail.com 
Running title: Two-Stage Operations in RSCO Patients

Word count for the text: 2,330

Word count for the abstract: 219

Keywords: Colon cancer; Obstruction; Ileostomy; Two-stage resection 


\section{Abstract}

\section{BACKGROUND:}

Longer procedure times and bigger wounds can result in more mortality and complications in patients

with acute RSCO with one stage surgery.

\section{OBJECTIVES}

To review two-stage operations for acute right-sided colonic obstruction (RSCO) in a single institution

\section{METHODS:}

The study reviewed the patients who underwent emergency surgery for acute RSCO in a tertiary

center from 2004-2018. First-stage operations other than diverting loop ileostomy, incomplete

obstructions that could be treated medically, or pathologies other than adenocarcinomas were excluded.

Perioperative data such as operations, operative times, lengths of stay, harvested lymph nodes, and any

complications were included. We assessed overall survival (OS) and disease-free survival (DFS) for the oncologic outcomes.

\section{RESULTS:}

Sixty-nine patients were included. Seven patients had surgical complications related to ileostomy.

Three of them died within 30 days of first admission. Thirty-one patients received a second-stage 
operation by right hemicolectomy. None had anastomosis leakage or 30-day mortality. Only $9.7 \%$ of patients had fewer than 12 harvested lymph nodes. One-year OS was 34\% vs. $89 \%$ between the two groups ( $\mathrm{P}<0.001)$. For 26 patients underwent curative resection of tumor, their 3-year DFS was $61.5 \%$

\section{CONCLUSIONS:}

A two-stage operation is associated with low mortality and morbidity rates in an emergency setting.

The subsequent right hemicolectomy can harvest more lymph nodes than emergency resection.

Long-term survival benefits can be expected.

\section{Introduction}

Colorectal cancer (CRC) is a very common disease. It is the third most commonly diagnosed

malignancy worldwide, with 1.8 million new cases and almost 861,000 deaths in 2018 according to

the World Health Organization GLOBOCAN database. The incidence of CRC in eastern Asia in 2018

was 3.06\%.[1] Although most patients with CRC have no symptoms and are diagnosed as a result of

screening, 7-47\% present with colonic obstruction as the first diagnosis.[2] Among these cases, about

20-30\% patients are of right-sided CRC.[3,4] For such cases, surgical options include resection of the tumor with a primary anastomosis with or without a temporary proximal diversion, resection without 
an anastomosis and with an end colostomy, or proximal diversion with a colostomy to stabilize the

patient, followed by elective definitive resection at a second operation and, occasionally,

self-expandable metallic stent (SEMS) placement.

Because of the lower bacterial counts[5] and better blood supply to the small intestine,[6] most

patients with right-sided colonic obstruction can be treated by resection of the tumor with a primary

anastomosis.[5,6] However, these patients are commonly old, often have some comorbidities and a

period of poor nutrient intake. Longer procedure times and bigger wounds can result in more

complications. Even the anastomosis itself can have leakage rates of 4.2-10\%,[7,8] which may lead to

the need for further surgery and increase patient mortality.[7,9,10]

Resection without an anastomosis avoids the risk of anastomotic leakage, but the procedure takes

more time than two-stage procedures such as SEMS placement and diverting loop ileostomy. To

minimize morbidity and mortality, most patients with a right-sided colonic obstruction receive

diverting loop ileostomy as the first-stage emergency operation in our hospital. The aim of this study

is to review the characteristics, surgical outcomes, complications, and outcomes of such cases.

\section{Methods}




\section{Patients}

From January 2004 to December 2018, all patients who underwent emergency surgery for acute obstructive right-sided CRC in the Tri-Service General Hospital, Taipei, Taiwan, were reviewed retrospectively. The right colon was defined as including the proximal two-thirds of the transverse colon, the ascending colon, and cecum by abdominal and pelvic computed tomography (CT) scans. Acute obstruction was defined based on clinical findings (abdominal pain, bloating, nausea or vomiting, and absence of flatus and/or bowel movement) and CT findings (tumor obstruction with proximal colon and/or small bowel dilatation). Emergency surgery was defined as the need to receive surgical intervention within $24 \mathrm{~h}$ of admission.

First-stage operations other than diverting loop ileostomy, incomplete obstructions that could be treated medically, or pathologies other than adenocarcinomas were excluded.

All CRC patients treated at our hospital between January 2004 to December 2018 were reviewed.

CRC diagnosis was histologic or based on radiologic findings. We had already followed the STROBE

Checklist for cohort studies. Tri-Service General Hospital institutional review board approved the study and waived the informed consent requirement owing to the investigator's retrospective nature.

(No. 1-108-05-038). All research was performed in accordance with the relevant guideline. 


\section{Procedures}

Patient characteristics such as age, gender, American Society of Anesthesiologists (ASA) score, body

mass index, and comorbidities were recorded. All operations were performed by seven colorectal

surgeons in our tertiary referral hospital. Clinical stage was determined by preoperative CT scans.

Pathology stage was reported by pathologists according to the seventh edition of the American Joint

Committee on Cancer. Perioperative data included first and second operations, first and second

operative times, first and second lengths of stay, and any complications. Overall survival (OS) was

determined by the patient's status at the last visit. Disease-free survival (DFS) was defined by the

length of time the patient survived after right hemicolectomy without evidence of cancer recurrence at follow-up.

\section{Statistical analysis}

Quantitative data are reported as medians and 25th and 75th percentiles. Categorical data are reported as absolute numbers and percentages. Patients who received only ileostomy and ileostomy plus right hemicolectomy were divided into two groups. For these cases, quantitative data were analyzed using the Mann-Whitney nonparametric U test. Categorical data were compared using chi-squared or Fisher's exact tests, as appropriate. OS and DFS were estimated using the Kaplan-Meier method. Log-rank analysis was used to determine statistical significance. A P value $<0.05$ was considered 
statistically significant. All analyses were performed using IBM SPSS Statistics for Windows (Version 25.0; IBM Corp., Armonk, NY, USA).

\section{Results}

In total, 69 of 70 patients receiving emergency diverting loop ileostomy over the 15 years of the study were included in the analysis; one patient who underwent explore laparotomy with right hemicolectomy was excluded. The median age of the patients was 77 years $(25$ th and 75 th percentiles: 64.5 and 83.5 years, respectively). Thirty-nine (56\%) patients were male. Forty-six patients had an ASA score of III-V. Fifty of the 69 cases had major comorbidities. The median operation time for diverting ileostomy was $54 \mathrm{~min}$ (42.5 and $77.5 \mathrm{~min}$ ), and the median length of stay was 9 days (7 and 15.5 days; Table 1).

Among the 69 patients, 31 received a second operation for resection of the tumor. Table 2 shows the characteristics of the two groups of patients. The median age of the patients who received right hemicolectomy was 68 years (25th and 75th percentiles: 59 and 78 years, respectively), which was significantly younger than those who received only ileostomy $(\mathrm{P}<0.001)$. The patients who received only ileostomy had more advanced clinical cancer stages $(\mathrm{P}<0.017)$ and longer hospital stays after ileostomy (medians: 10.5 vs. 8 days; $\mathrm{P}<0.039$ ). However, no significant difference was found in the 
operation time for ileostomy between the two groups (55.5 vs. 51 mins). Most patients in both groups had major comorbidities.

Seven patients had surgical complications related to ileostomy. Six of these received only ileostomy.

The other patient who suffered an ileostomy prolapse subsequently received right hemicolectomy.

Three of the patients died within 30 days of first admission. All of these patients had clinical stage IV

colon cancer. Two of the patients died from nosocomial pneumonia, and the other one died from acute myocardial infarction (Table 3).

For patients who received a second operation, only three of them had surgical complications related to right hemicolectomy; none had anastomosis leakage or 30-day mortality (Table 4).

The mean follow-up time was $8.37 \pm 1.14$ months in the patients who received only diverting loop ileostomy, and 109.11 \pm 13.42 months in those who received two-stage operations. During follow-up, 19 of 38 patients who received only diverting ileostomy and seven of 31 who received two-stage operations died. The median survival time was 7.51 months for patients who received only ileostomy; this end point was not reached for the other group of patients. One-year OS was $34 \%$ vs. $89 \%$, respectively, between the two groups ( $\mathrm{P}<0.001$; Fig. 1).

Thirty-one patients received a second-stage operation by right hemicolectomy (four by laparoscopic surgery). In three of the patients, fewer than 12 lymph nodes were harvested. The mean number of harvested lymph nodes was 17 (13 and 21, respectively). Comparing tumor stages II, III, and IV, the 
1-year OS rates were $100 \%, 90.9 \%$, and $87.5 \%$, respectively, and the 3 -year OS rates were $100 \%$,

$70.1 \%$, and $62.5 \%$, respectively. No significant difference was seen in OS between the two groups (P

$=0.211$ ); however, a trend was observed (Fig. 2). Among the patients, 26 underwent curative resection of tumor and nine had a tumor recurrence. Three-year DFS was $61.5 \%$. The median DFS was not reached during the follow-up period (Fig. 3). Comparing tumor stages II, III, and IV, the 3-year DFS rates were $100 \%, 57.8 \%$, and $20 \%$, respectively. DFS was significantly different between patients with stage II and IV tumors ( $\mathrm{P}=0.017$; Fig. 4).

\section{Discussion}

Elderly patients are known to have high rates of emergency colorectal surgery for tumor obstructions or perforations.[11] The median age of the patients in our study was 77 years, consistent with the literature. Patients who have obstructive CRCs also have more comorbidities and higher ASA tumor scores than those who have nonobstructive CRCs.[12,2] In the present study, 46 of the 69 patients had ASA scores of III-V at first admission, and 50 had major comorbidities. These data indicate the fragility of our patients.

Although some reports have advocated the benefits of palliative resection of the primary colon tumor for patients with unresectable metastatic CRCs, this remains controversial.[13-15] In the present study, 
38 of the 69 patients received only ileostomy. It is not surprising that most of these patients had an unresectable metastatic CRC. Fourteen patients in this series had clinical stage II or III CRCs and did not receive curative treatment. The reasons for this included major comorbidities, poor performance status, incurable second cancers, and old age.

Unlike left-sided tumor obstructions, acute tumor obstructions in the right colon are usually treated by resection with a primary ileocolic anastomosis. However, the reported leakage rate is $4.3-16.4 \%$, which could lead to death in some patients. $[2,16,3,17]$ In the literature, the mortality rate for emergency surgery for proximal colon tumor obstruction ranges from 10.1 to $14.7 \%$.[18,3,17] Although our patients had higher ASA tumor grades and more comorbidities compared with those in other reports, $[18,3]$ the surgical complications rate, including the mortality rate for first-stage operations, was extremely low. There are some possible reasons for this. First, we avoided prolonged operation times in emergency settings. The median operation time for an ileostomy was $<1 \mathrm{~h}$, which is shorter than that needed for resection of the obstructed tumor. Second, to make an ileostomy, we only need to create a small incision. Compared with the long midline incisions needed for laparotomy, an incision at the lower right quadrant of the abdomen is less painful. Third, we did not perform an anastomosis, meaning that we avoided the risk of anastomotic leakage, which could lead to the need for another operation, prolong the length of hospital stay, and increase the mortality rate. 
The surgical complications of the second operation in this study were minor. No anastomotic leakage or 30-day mortality was found, even though 18 of 31 tumors had ASA scores of III or IV at the first operation. The patients could build up their nutrition, stabilize vital signs, and have better circulation during the interval between operations. All of these factors probably improved the outcomes of the second operations.

Emergency resection for an obstructing CRC can make it difficult to harvest a sufficient number of lymph nodes because of the dilated proximal bowel and limited surgical field. In the literature, $19.3-19.8 \%$ of patients had inadequate numbers of harvested lymph nodes.[2,19] This could lead to tumor understaging and poorer prognosis, especially among elderly patients.[20,21] In our study, 31 patients received two-stage operations. Less than $10 \%$ of patients had fewer than 12 harvested lymph nodes, and 74\% had lymph node invasion, which is higher than that in previous reports.[22,2] Although the case number was small, four patients received laparoscopic right hemicolectomy with D3 lymphadenectomy at the second operation. Better oncological and cosmetic outcomes can be expected compared with emergency laparotomy.

It is not surprising that the patients who received only diverting loop ileostomy had significantly shorter OS. Even though 24 of 38 patients had a clinical stage IV CRC, their OS was shorter than that reported previously.[23] This result could be explained by the old age and multiple comorbidities of these patients. The patients who received two-stage operations had longer OS. Although five patients 
who had unresectable metastatic CRCs received a right hemicolectomy, the OS showed no significant difference among patients with stage II, III, or IV tumors. This result may imply the benefit of resecting primary tumors, even though the case number was small.[13]

The patients who received curative two-stage operations had better DFS than that reported in the literature.[24] This may be explained by our use of elective curative surgery and adequate numbers of harvested lymph nodes. However, some patients who were too weak to undergo further surgery were excluded. Thus, the long-term survival benefit of two-stage operations remains to be proven by further prospective studies. SEMS used for obstructive CRCs as a bridge to surgery help avoid the need for emergency surgery and reduce the risk of postoperative complications and mortality. It seems to have the same benefits as diverting loop ileostomy and avoids the creation of a stoma. However, SEMS insertion for right-sided tumor obstruction is associated with a higher technical failure rate than that for left-sided tumor obstruction.[25,26] Once perforation occurs, the patients' oncologic outcome will be significantly worse.[27] It must be noted that the stent procedure can increase the numbers of circulating tumor cells by compressing the tumor, and this is related to worse oncologic outcomes.[28,29] Therefore, SEMS insertion for right-sided colon obstruction is mainly recommended as an alternative in a palliative setting.[30] Furthermore, stent insertion itself can be a risk factor of colonic perforation during chemotherapy for patients with stage IV tumors, especially in combination with bevacizumab therapy.[15,31,32] In this study, $63 \%$ of the patients who received only diverting 
ileostomy had a stage IV CRC. Stent insertion for such patients might impair their survival during

chemotherapy.

Our study had several limitations. First, it was a retrospective cohort analysis, and all cases

were from a single tertiary center, which could have introduced bias in this 15 -year series. Second, most of the patients with an acute right-sided colonic obstruction in our hospital received two-stage operations. Thus, we could not compare the outcomes between emergency resection and two-stage operations in our institute. Third, only 69 patients were included in our study, and this small sample size might have caused some bias.

\section{Conclusions}

Although a two-stage operation by diverting loop ileostomy is not usually the first procedure

considered for acute right-sided colonic obstruction because of the need to create a temporary stoma, it is associated with low mortality and morbidity rates in an emergency setting. Diverting loop ileostomy avoids the possible adverse oncologic outcomes of SEMS, and the subsequent right hemicolectomy can harvest more lymph nodes than can emergency resection. Long-term survival benefits can be expected from this approach. 


\section{Declarations}

\section{Consent to publish:}

Not applicable

\section{Availability of data and materials:}

All the data regarding the findings are available within the manuscript.

\section{Authors' contributions:}

Chun-Wei Yu, MD: patient selection, data collection, paper writing, surgical operations

Nien-Ying Tsai: data collection

Cheng-Wen Hsiao, MD: patient selection, surgical operations, data contribution

Shu-Wen Jao, MD: patient selection, surgical operations, data contribution

Yi-Chiao Cheng, MD: design the study, patient selection, statistical analysis, paper writing, approval of the final version of the paper, surgical operations

\section{Acknowledgement:}

We would like to acknowledge the data collection and patient treatment provided by

the members of the Division of Colon and Rectal Surgery, Department of Surgery, and 15 
Division of Urological Surgery, Department of Surgery.

\section{Compliance with Ethical Standards:}

\section{Funding:}

This study was not funded

\section{Conflict of Interest:}

All authors have no conflict of interest

Ethical approval and informed consent: Tri-Service General Hospital

institutional review board approved the study and waived the informed consent requirement owing to the investigator's retrospective nature.

\section{References}

1. The Global Cancer Observatory. (2019) Available via World Health Organization.

https://gco.iarc.fr/today/data/factsheets/cancers/10_8_9-Colorectum-fact-sheet.pdf.

2. Faucheron JL, Paquette B, Trilling B, Heyd B, Koch S, Mantion G (2018) Emergency surgery for obstructing colonic cancer: a comparison between right-sided and left-sided lesions. Eur J Trauma

Emerg Surg 44 (1):71-77. doi:10.1007/s00068-017-0766-X 
3. Aslar AK, Ozdemir S, Mahmoudi H, Kuzu MA (2011) Analysis of 230 cases of emergent surgery for obstructing colon cancer--lessons learned. J Gastrointest Surg 15 (1):110-119. doi:10.1007/s11605-010-1360-2

4. Pisano M, Zorcolo L, Merli C, Cimbanassi S, Poiasina E, Ceresoli M, Agresta F, Allievi N, Bellanova G, Coccolini F, Coy C, Fugazzola P, Martinez CA, Montori G, Paolillo C, Penachim TJ, Pereira B, Reis T, Restivo A, Rezende-Neto J, Sartelli M, Valentino M, Abu-Zidan FM, Ashkenazi I, Bala M, Chiara O, De' Angelis N, Deidda S, De Simone B, Di Saverio S, Finotti E, Kenji I, Moore E, Wexner S, Biffl W, Coimbra R, Guttadauro A, Leppaniemi A, Maier R, Magnone S, Mefire AC,

Peitzmann A, Sakakushev B, Sugrue M, Viale P, Weber D, Kashuk J, Fraga GP, Kluger I, Catena F, Ansaloni L (2018) 2017 WSES guidelines on colon and rectal cancer emergencies: obstruction and perforation. World J Emerg Surg 13:36. doi:10.1186/s13017-018-0192-3

5. Lyra A, Forssten S, Rolny P, Wettergren Y, Lahtinen SJ, Salli K, Cedgard L, Odin E, Gustavsson B, Ouwehand AC (2012) Comparison of bacterial quantities in left and right colon biopsies and faeces.

World J Gastroenterol 18 (32):4404-4411. doi:10.3748/wjg.v18.i32.4404

6. Cuffy M, Abir F, Audisio RA, Longo WE (2004) Colorectal cancer presenting as surgical emergencies. Surg Oncol 13 (2-3):149-157. doi:10.1016/j.suronc.2004.08.002 
7. Gessler B, Eriksson O, Angenete E (2017) Diagnosis, treatment, and consequences of anastomotic leakage in colorectal surgery. International journal of colorectal disease 32 (4):549-556. doi:10.1007/s00384-016-2744-X

8. Nors J, Sommer T, Wara P (2018) Leakage Rate After Laparoscopic Ileocolic Intracorporeal Anastomosis. J Laparoendosc Adv Surg Tech A 28 (11):1287-1293. doi:10.1089/lap.2018.0219

9. Vasiliu EC, Zarnescu NO, Costea R, Neagu S (2015) Review of Risk Factors for Anastomotic Leakage in Colorectal Surgery. Chirurgia (Bucharest, Romania : 1990) 110 (4):319-326

10. Nasiri S, Mirminachi B, Taherimehr R, Shadbakhsh R, Hojat M (2017) The Effect of Omentoplasty on the Rate of Anastomotic Leakage after Intestinal Resection: A Randomized Controlled Trial. The American surgeon 83 (2):157-161

11. Basili G, Lorenzetti L, Biondi G, Preziuso E, Angrisano C, Carnesecchi P, Roberto E, Goletti O (2008) Colorectal cancer in the elderly. Is there a role for safe and curative surgery? ANZ J Surg 78 (6):466-470. doi:10.1111/j.1445-2197.2008.04536.x

12. Finan PJ, Campbell S, Verma R, MacFie J, Gatt M, Parker MC, Bhardwaj R, Hall NR (2007) The management of malignant large bowel obstruction: ACPGBI position statement. Colorectal Dis 9 Suppl 4:1-17. doi:10.1111/j.1463-1318.2007.01371.x 
13. Ishihara S, Nishikawa T, Tanaka T, Tanaka J, Kiyomatsu T, Kawai K, Hata K, Nozawa H,

Kazama S, Yamaguchi H, Sunami E, Kitayama J, Sugihara K, Watanabe T (2015) Benefit of primary

tumor resection in stage IV colorectal cancer with unresectable metastasis: a multicenter retrospective

study using a propensity score analysis. International journal of colorectal disease 30 (6):807-812.

doi:10.1007/s00384-015-2228-4

14. Ishihara S, Hayama T, Yamada H, Nozawa K, Matsuda K, Miyata H, Yoneyama S, Tanaka T,

Tanaka J, Kiyomatsu T, Kawai K, Nozawa H, Kanazawa T, Kazama S, Yamaguchi H, Sunami E,

Kitayama J, Hashiguchi Y, Sugihara K, Watanabe T (2014) Prognostic impact of primary tumor

resection and lymph node dissection in stage IV colorectal cancer with unresectable metastasis: a

propensity score analysis in a multicenter retrospective study. Ann Surg Oncol 21 (9):2949-2955.

doi:10.1245/s10434-014-3719-1

15. Lee WS, Baek JH, Kang JM, Choi S, Kwon KA (2012) The outcome after stent placement or surgery as the initial treatment for obstructive primary tumor in patients with stage IV colon cancer.

Am J Surg 203 (6):715-719. doi:10.1016/j.amjsurg.2011.05.015

16. Lee YM, Law WL, Chu KW, Poon RT (2001) Emergency surgery for obstructing colorectal cancers: a comparison between right-sided and left-sided lesions. J Am Coll Surg 192 (6):719-725 
17. Frago R, Biondo S, Millan M, Kreisler E, Golda T, Fraccalvieri D, Miguel B, Jaurrieta E (2011)

Differences between proximal and distal obstructing colonic cancer after curative surgery. Colorectal Dis 13 (6):e116-122. doi:10.1111/j.1463-1318.2010.02549.x

18. Biondo S, Pares D, Frago R, Marti-Rague J, Kreisler E, De Oca J, Jaurrieta E (2004) Large bowel obstruction: predictive factors for postoperative mortality. Diseases of the colon and rectum 47

(11):1889-1897

19. Chin CC, Wang JY, Changchien CR, Huang WS, Tang R (2010) Carcinoma obstruction of the proximal colon cancer and long-term prognosis--obstruction is a predictor of worse outcome in TNM stage II tumor. International journal of colorectal disease 25 (7):817-822.

doi:10.1007/s00384-010-0904-y

20. Babcock BD, Aljehani MA, Jabo B, Choi AH, Morgan JW, Selleck MJ, Luca F, Raskin E, Reeves ME, Garberoglio CA, Lum SS, Senthil M (2018) High-Risk Stage II Colon Cancer: Not All Risks Are Created Equal. Ann Surg Oncol 25 (7):1980-1985. doi:10.1245/s10434-018-6484-8

21. Reha J, Mukkamalla SKR, Rathore R, Somasundar PS (2018) Adequate lymph node evaluation in the elderly is associated with improved survival in patients with stage I-III colon cancer: A validation study using the National Cancer Data Base. Eur J Surg Oncol 44 (1):148-156.

doi:10.1016/j.ejso.2017.11.005 
22. Yang Z, Wang L, Kang L, Xiang J, Peng J, Cui J, Huang Y, Wang J (2011) Clinicopathologic characteristics and outcomes of patients with obstructive colorectal cancer. J Gastrointest Surg 15 (7):1213-1222. doi:10.1007/s11605-011-1563-1

23. Arnold D, Lueza B, Douillard JY, Peeters M, Lenz HJ, Venook A, Heinemann V, Van Cutsem E, Pignon JP, Tabernero J, Cervantes A, Ciardiello F (2017) Prognostic and predictive value of primary tumour side in patients with RAS wild-type metastatic colorectal cancer treated with chemotherapy and EGFR directed antibodies in six randomized trials. Ann Oncol 28 (8):1713-1729.

doi:10.1093/annonc/mdx175

24. Ji WB, Kwak JM, Kang DW, Kwak HD, Um JW, Lee SI, Min BW, Sung NS, Kim J, Kim SH

(2017) Clinical benefits and oncologic equivalence of self-expandable metallic stent insertion for right-sided malignant colonic obstruction. Surg Endosc 31 (1):153-158.

doi:10.1007/s00464-016-4946-2

25. Yoon JY, Jung YS, Hong SP, Kim TI, Kim WH, Cheon JH (2011) Clinical outcomes and risk factors for technical and clinical failures of self-expandable metal stent insertion for malignant colorectal obstruction. Gastrointest Endosc 74 (4):858-868. doi:10.1016/j.gie.2011.05.044

26. Cho YK, Kim SW, Lee BI, Lee KM, Lim CH, Kim JS, Chang JH, Park JM, Lee IS, Choi MG, Choi KY, Chung IS (2011) Clinical outcome of self-expandable metal stent placement in the 
management of malignant proximal colon obstruction. Gut Liver 5 (2):165-170.

doi:10.5009/gnl.2011.5.2.165

27. Sloothaak DA, van den Berg MW, Dijkgraaf MG, Fockens P, Tanis PJ, van Hooft JE, Bemelman

WA, collaborative Dutch Stent-In study g (2014) Oncological outcome of malignant colonic obstruction in the Dutch Stent-In 2 trial. The British journal of surgery 101 (13):1751-1757.

doi:10.1002/bjs.9645

28. Maruthachalam K, Lash GE, Shenton BK, Horgan AF (2007) Tumour cell dissemination following endoscopic stent insertion. The British journal of surgery 94 (9):1151-1154.

doi:10.1002/bjs.5790

29. Steinert EM, Schwartz RH, Singh NJ (2012) At low precursor frequencies, the T-cell response to chronic self-antigen results in anergy without deletion. Eur J Immunol 42 (11):2875-2880.

doi:10.1002/eji.201242518

30. van Hooft JE, van Halsema EE, Vanbiervliet G, Beets-Tan RG, DeWitt JM, Donnellan F,

Dumonceau JM, Glynne-Jones RG, Hassan C, Jimenez-Perez J, Meisner S, Muthusamy VR, Parker

MC, Regimbeau JM, Sabbagh C, Sagar J, Tanis PJ, Vandervoort J, Webster GJ, Manes G, Barthet MA,

Repici A, European Society of Gastrointestinal E (2014) Self-expandable metal stents for obstructing

colonic and extracolonic cancer: European Society of Gastrointestinal Endoscopy (ESGE) Clinical

Guideline. Endoscopy 46 (11):990-1053. doi:10.1055/s-0034-1390700 
31. Small AJ, Coelho-Prabhu N, Baron TH (2010) Endoscopic placement of self-expandable metal stents for malignant colonic obstruction: long-term outcomes and complication factors. Gastrointest Endosc 71 (3):560-572. doi:10.1016/j.gie.2009.10.012

32. Pacheco-Barcia V, Mondejar R, Martinez-Saez O, Longo F, Moreno JA, Rogado J, Donnay O,

Santander C, Carrato A, Colomer R (2019) Safety and Oncological Outcomes of Bevacizumab

Therapy in Patients With Advanced Colorectal Cancer and Self-expandable Metal Stents. Clinical colorectal cancer. doi:10.1016/j.clcc.2019.05.009

\section{Figure legends}

Fig. 1 The median survival time was 7.51 months for patients who received only ileostomy; One-year

OS was $34 \%$ vs. $89 \%$ between the two groups $(\mathrm{P}<0.001)$.

Fig. 2 Comparing tumor stages II, III, and IV, no significant difference was seen in OS between the two groups $(\mathrm{P}=0.211)$.

Fig. 3 Three-year DFS of ileostomy and curative right hemicolectomy group patients was $61.5 \%$, $\mathrm{n}=26$.

Fig. 4 Comparing tumor stages II, III, and IV, DFS was significantly different between patients with stage II and IV tumors $(\mathrm{P}=0.017)$. 
Figures

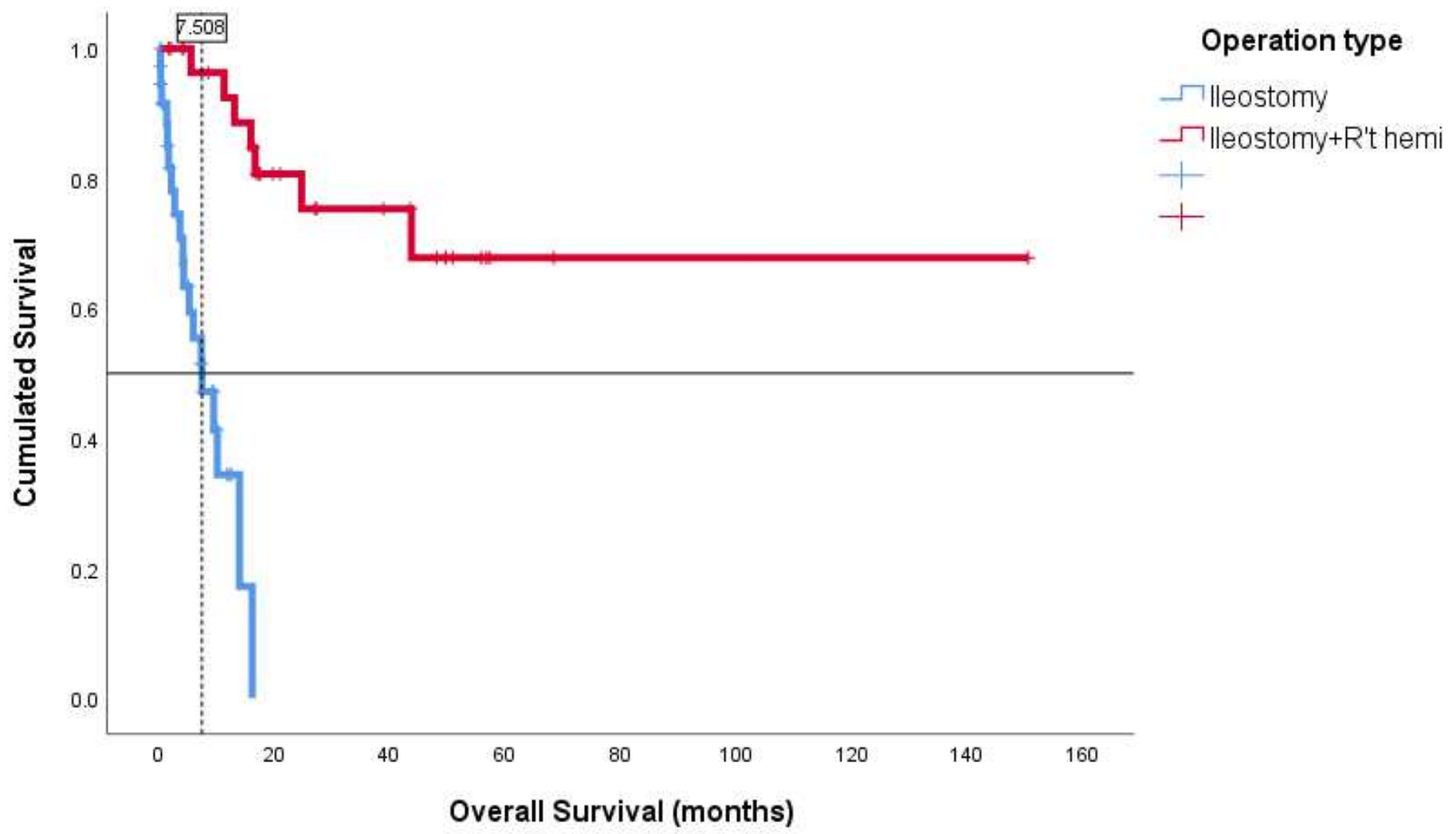

\section{Figure 1}

The median survival time was 7.51 months for patients who received only ileostomy; One-year OS was $34 \%$ vs. $89 \%$ between the two groups $(P<0.001)$. 


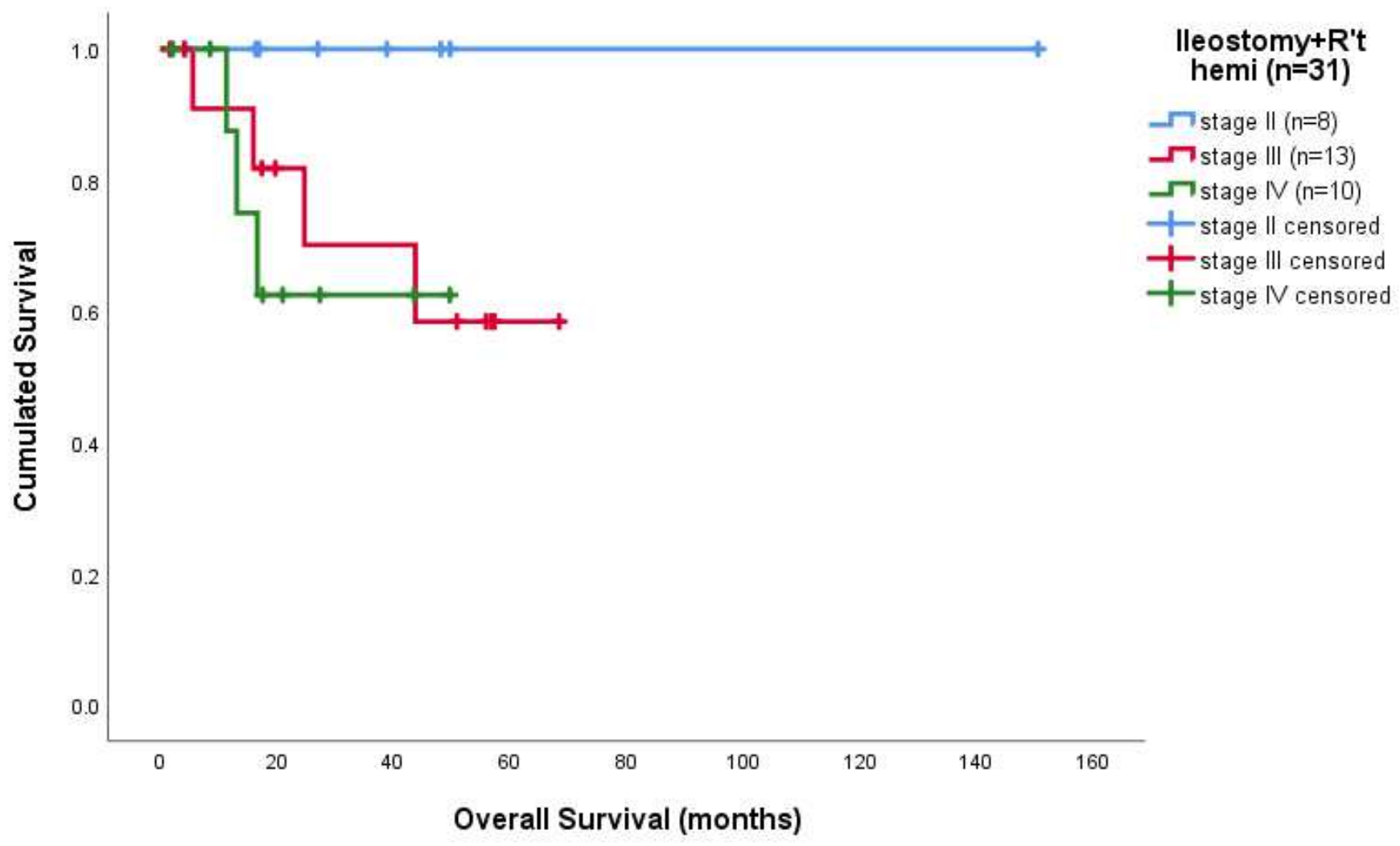

Figure 2

Comparing tumor stages II, III, and IV, no significant difference was seen in OS between the two groups ( $=0.211)$. 


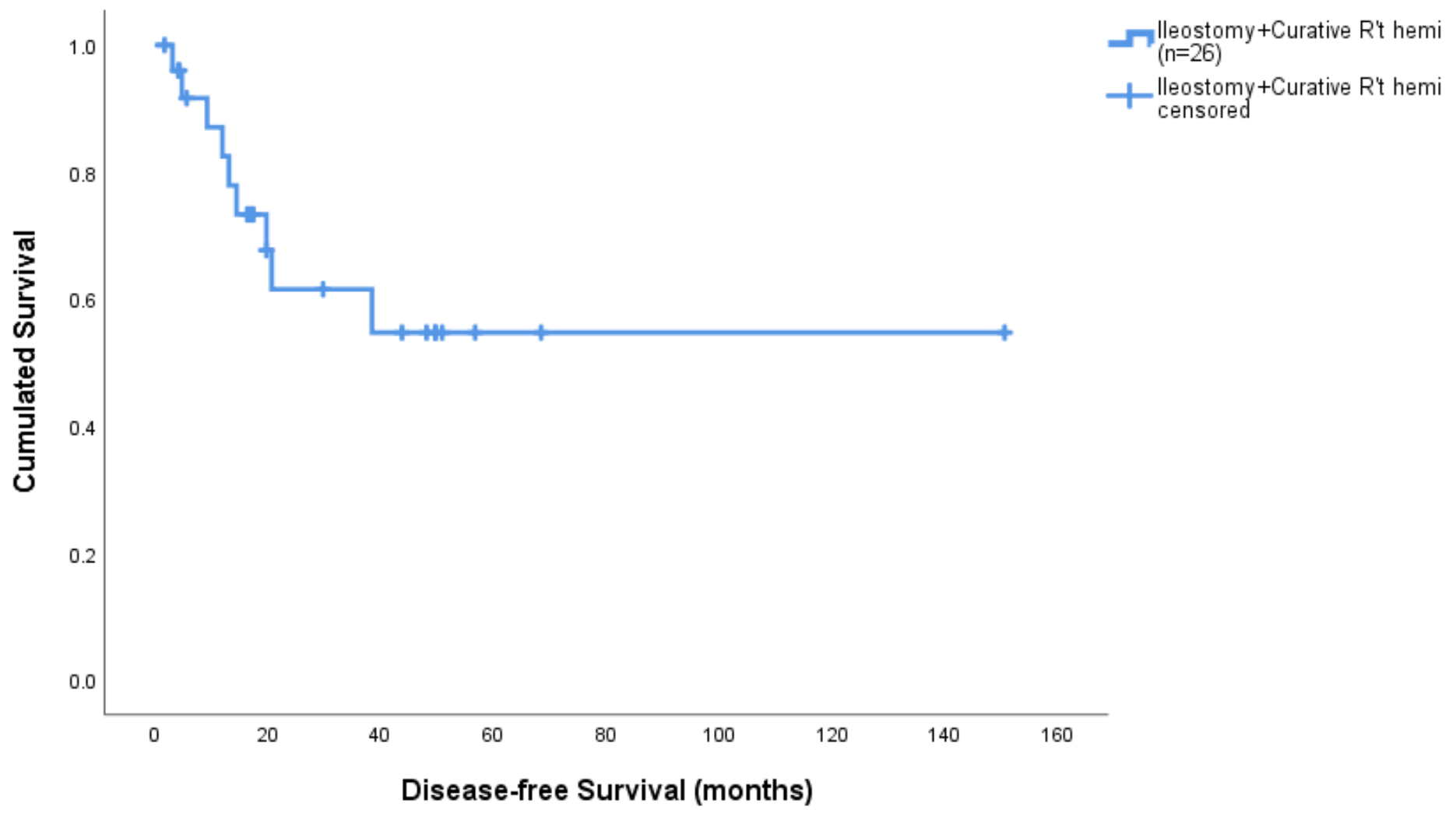

Figure 3

Three-year DFS of ileostomy and curative right hemicolectomy group patients was $61.5 \%, n=26$ 


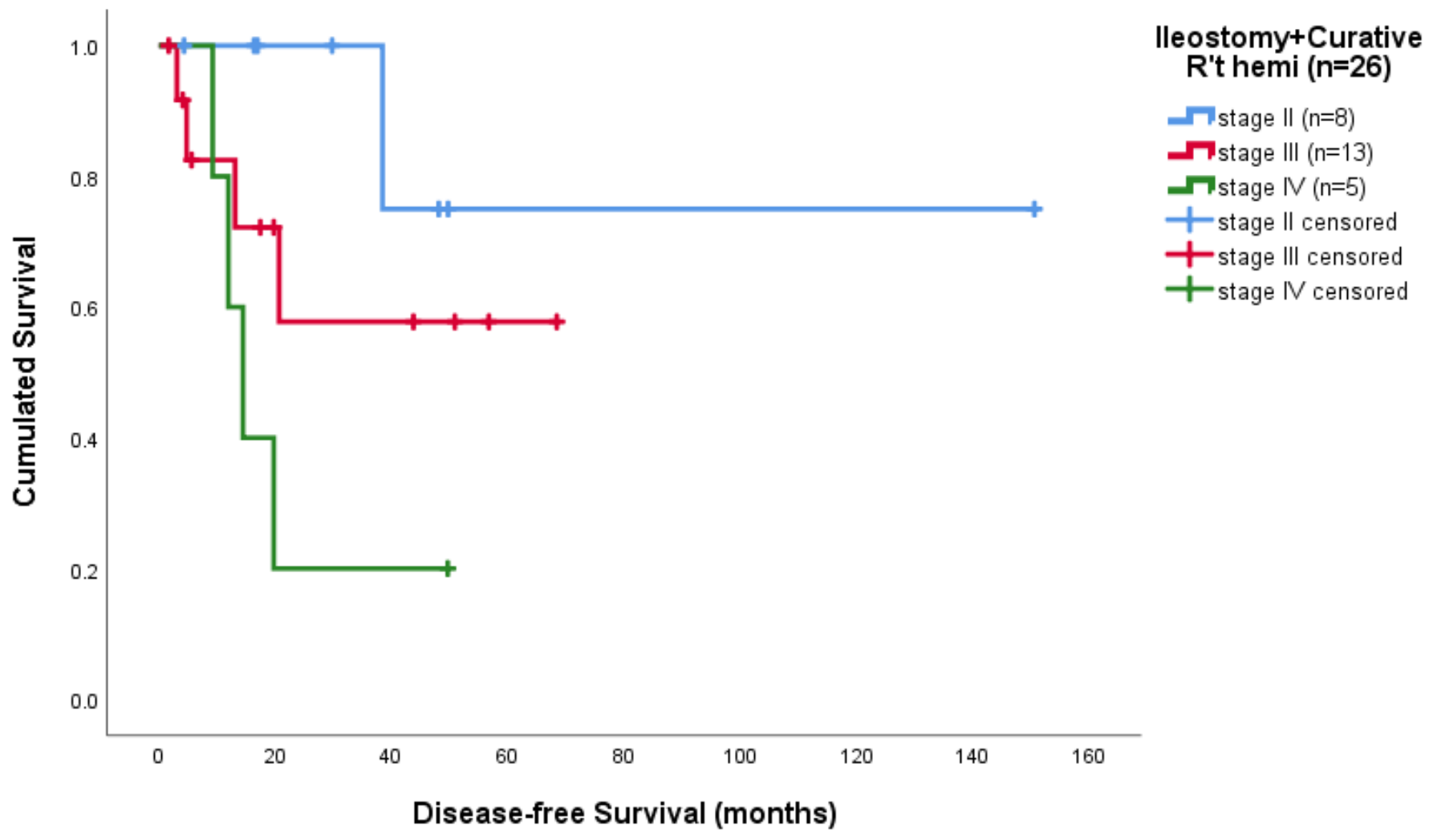

Figure 4

Comparing tumor stages II, III, and IV, DFS was significantly different between patients with stage II and IV tumors $(P=0.017)$. 